\title{
STRATEGI PENGELOLAAN SAMPAH DI TEMPAT PEMBUANGAN AKHIR (TPA) KABUPATEN BENGKULU SELATAN TAHUN 2012
}

\author{
Yogi Kosmanto ${ }^{1)}$, Rohidin ${ }^{2)}$, dan Bieng Brata ${ }^{3)}$ \\ 1) Mahasiswa Program Pasca Sarjana Pengelolaan Sumber Daya Alam dan Lingkungan \\ Fakultas Pertanian UNIB \\ 2) Staf Pengajar Luar Biasa Fakultas Pertanian UNIB \\ 3). Staf Pengajar Fakultas Pertanian UNIB
}

\begin{abstract}
ABSTRAK
Penelitian ini bertujuan untuk mengetahui strategi pengelolaan sampah di TPA, dan mengetahui faktor yang akan mempercepat proses pengelolaan sampah, mengetahui faktor penghambat proses pengelolaan sampah, mengetahui peluang yang dapat diraih sehubungan dengan pelaksanaan pengelolaan sampah, mengetahui ancaman yang akan menjadi penghambat proses pengelolaan sampah. Waktu penelitian dilakukan pada bulan Januari tahun 2012 hingga bulan Maret tahun 2012 di Tempat Pembuangan Akhir Kabupaten Bengkulu Selatan. Jenis penelitian ini adalah penelitian survey kualitatif dengan menggunakan metode analisis SWOT (Strengh, Weaknesses, Opportunities, Threats) untuk menganalisis strategi pengelolaan sampah agar tidak menimbulkan dampak negatif di TPA. Hasil penelitian menunjukkan bahwa kekuatan (strength) yang dimiliki adalah, Adanya dukungan dari Pemerintah Daerah Kabupaten Bengkulu Selatan dilihat dari tanggapan responden $52 \%$ menyatakan setuju, $42 \%$ sangat setuju, dan 6\% menyatakan tidak setuju.Tersedianya Sumber Daya Manusia (SDM) yang cukup banyak yang dilihat dari $66 \%$ responden menyatakan setuju, $27 \%$ responden menyatakan sangat setuju dan $7 \%$ responden kurang setuju. Tersedianya kotak sampah yang cukup yang dilihat dari $68 \%$ menyatakan setuju, 19\% sangat setuju dan 13\% tidak setuju. Kelemahannya adalah pegawai Dinas Kebersihan Pertamanan dan Tata Kota kurang aktif dan belum diberdayakan maksimal yang dilihat dari 53\% responden setuju, 19\% kurang setuju, $15 \%$ tidak setuju dan $13 \%$ sangat setuju. pendistribusian SDM belum merata dilihat dari $49 \%$ responden menyatakan setuju, $37 \%$ menyatakan kurang setuju (ini mungkin disebabkan karna ketidak tahuan responden), $10 \%$ sangat setuju dan 4\% tidak setuju .Masih kurangnya sosialisasi kepada masyarakat tentang sampah organik dan anorganik serta cara pemisahannya dilihat dari 54\% responden menyatakan setuju, 28\% sangat setuju, 18\% tidak setuju. Peluang yang dimiliki adalah sampah organik dapat dijadikan pupuk kompos dan makanan ternak, sampah anorganik dapat didaur ulang. Sedangkan ancaman yang dihadapi adalah kurangnya sarana pengangkut sampah, belum adanya SDM yang menguasai teknik mesin pengelola sampah dan tenaga ahli di bidang pengelolaan sampah. Kesimpulan dari penelitian ini adalah Strategi yang direkomendasikan untuk mengelola sampah di TPA Kabupaten Bengkulu Selatan yaitu memanfaatkan seluruh kekuatan yang dimiliki Dinas Kebersihan Pertamanan dan Tata Kota serta memberdayakan masyarakat, dan pemulung untuk menangkap peluang yang ada.
\end{abstract}

Kata Kunci: Sampah, Strategi, Pengelolaan.

\section{PENDAHULUAN}

Seiring dengan bergulirnya waktu, Kabupaten Bengkulu Selatan semakin berkembang. Perkembangan ini juga diiringi dengan pertambahan jumlah penduduk dan peningkatan aktifitas mereka tentunya, dimana peningkatan aktifitas tersebut, menyebabkan terjadinya peningkatan volume sampah.

Sampah merupakan konsekuensi dari aktivitas manusia. Setiap aktivitas manusia 
menghasilkan sampah. Jumlah atau volume sampah sebanding dengan tingkat konsumsi kita terhadap barang/material yang kita gunakan sehari-hari. Sampah adalah suatu bahan yang terbuang dari sumber hasil aktifitas manusia maupun alam yang belum memiliki nilai ekonomis (Purwanti, 2007).

Kabupaten Bengkulu Selatan yang beribukota Manna, mempunyai luas $1.186,10 \mathrm{~km}^{2}$ dengan jumlah penduduk 142.940 jiwa, (Bengkulu Selatan Dalam Angka, 2011). Tahun 2003 Kabupaten Bengkulu Selatan dipecah menjadi tiga (3) kabupaten karena terjadi pemekaran wilayah, yaitu Kabupaten Bengkulu Selatan itu sendiri, Kabupaten Kaur dan Kabupaten Seluma. Sejak berdirinya kedua Kabupaten Pemekaran tersebut, Kabupaten Bengkulu Selatan semakin di tuntut untuk lebih maju dan dapat menjadi contoh dalam segala bidang, baik itu di bidang pembangunan fisik, sumber daya manusia, pendidikan dan kesehatan. Bidang Kesehatan sangat perlu di perhatikan, mulai dari faktor kebersihan lingkungan rumah tangga, masyarakat, pasar, rumah sakit dan fasilitas umum lainnya serta Tempat Pembuangan Sampah Akhir (TPA) yang sering luput dari perhatian masyarakat dan pemerintah.

Tempat Pembuangan Akhir (TPA) sampah di Ibu Kota Kabupaten ini terletak di Desa Pagar Dewa Kecamatan Kota Manna Kabupaten Bengkulu Selatan yang mempunyai luas lebih kurang 3,5 Ha dan berjarak $100 \mathrm{~m}$ dari pemukiman penduduk, dimana lokasi tersebut terletak diatas jurang sungai. Sampah yang dibuang ke TPA ini mencapai 5 (lima) ton perhari, yang terdiri dari sampah dari Pasar Ampera, Pasar Kota Medan, sampah rumah tangga dan perkantoran (Dinas Kebersihan Pertamanan dan Tata Kota, 2011). Sampai saat ini sampah tersebut dibiarkan begitu saja, tanpa dikelola/belum dikelola sebagaimana mestinya. Hal ini akan berdampak buruk pada kesehatan masyarakat di sekitar TPA dan air sungai yang berada di bawah jurang TPA tersebut.
Berdasarakan pada permasalahan seperti tersebut diatas, maka peneliti tertarik untuk meneliti (menganalisis) strategi pengelolaan sampah di TPA Kabupaten Bengkulu Selatan.

\section{METODE PENELITIAN}

Penelitian ini dilaksanakan mulai dari bulan Pebruari 2012 hingga Maret 2012. Lokasi penelitian di Tempat Pembuangan Akhir Kabupaten Bengkulu Selatan. Untuk menganalisis strategi pengelolaan sampah agar tidak menimbulkan dampak negatif di TPA. Populasi dalam penelitian ini adalah seluruh masyarakat yang tinggal di sekitar TPA, akan tetapi sampel hanya diambil sebanyak 60 orang dengan menggunakan metode purposive sampling.Kegiatan yang akan dilakukan dalam rangka mendukung penelitian ini adalah sebagai berikut: Melakukan pengumpulan data, mengumpulkan data primer dan sekunder, dan melakukan analisis data.

Data yang dikumpulkan terdiri dari data primer dan data sekunder yang dikumpulkan dengan cara berikut: Data primer, diperoleh dengan cara melakukan penelitian langsung yaitu melakukan wawancara dengan penduduk yang menetap di sekitar TPA, data sekunder, diperoleh dengan mengambil data pada dinas instansi yang membidangi objek yang akan diteliti meliputi jumlah petugas kebersihan, jumlah petugas pengangkut sampah dan data pendukung lainnya pada dinas instansi terkait.

Analisis masalah terhadap strategi pengelolaan sampah di TPA Kabupaten Bengkulu Selatan dilakukan berdasarkan pada semua hasil analisis data yang ada dengan mempertimbangkan masukanmasukan dari berbagai sumber yang diperoleh selama penelitian serta dari berbagai literatur pendukung, termasuk didalamnya berupa hasil kajian/studi yang telah dilakukan oleh pihak-pihak lain. Selanjutnya dari analisis tersebut ditentukan strategi pengelolaan sampah 
yang dapat menjadi pertimbangan dalam menentukan strategi pengelolaan sampah di TPA khususnya terkait dengan upaya mengurangi dampak negatif yang ditimbulkan oleh kegiatan tersebut.

Untuk menyusun strategi-strategi pengelolaan sampah digunakan analisis SWOT, analisis SWOT menjelaskan proses analisis kasus berikut perumusan strategi dan formulasi yang dipilih.

Menurut Rangkuty (2000:31-32) alat yang dapat digunakan untuk menyusun faktor-faktor strategi adalah SWOT. Matriks ini dapat menggambarkan secara jelas bagaimana peluang dan ancaman eksternal yang dihadapi dapat disesuaikan dengan kekuatan dan kelemahan yang dimiliki. Matrik ini dapat menghasilkan empat set kemungkinan alternatif strategi yaitu: Staretgi SO, adalahs trategi yang disusun dengan cara menggunakan semua kekuatan untuk merebut peluang. Strategi ST, adalah strategi yang disusun dengan cara menggunakan semua kekuatan untuk mengatasi ancaman. Strategi WO, Strategi yang disusun dengan cara meminimalkan kelemahaan untuk memanfaatkan peluang yang ada. Strategi WT, strategi yang disusun dengan cara meminimalkan kelemahaan untuk menghindari ancaman.

\section{HASIL DAN PEMBAHASAN}

\section{Gambaran Umum Kabupaten Bengkulu Selatan}

Kabupaten Bengkulu Selatan terletak di sebelah Selatan Provinsi Bengkulu dan Sebelah Barat Bukit Barisan. Luas Wilayah Administrasi mencapai \pm $1.186,10 \mathrm{~km}^{2}$. Terletak pada $4^{\circ} 10 \mathrm{mnt}-4^{\circ}$ 34 mnt Lintang Selatan dan $102^{\circ} 48 \mathrm{mnt}$ $103^{\circ} 17$ mnt Bujur Timur. Kabupaten Bengkulu Selatan berbatasan dengan:

- Sebelah Utara berbatasan dengan Kabupaten Seluma

- Sebelah Timur berbatasan dengan Provinsi Sumatera Selatan

- Sebelah Selatan berbatasan dengan Kabupaten Kaur

- Sebelah Barat berbatasan dengan Lautan Hindia.

Kabupaten Bengkulu Selatan terdiri dari 11 kecamatan, yang salah satu kecamatannya adalah Kecamatan Kota Manna, tempat dilakukannya penelitian ini. Penduduk dan Mata Pencaharian Jumlah penduduk Kabupaten Bengkulu Selatan Tahun 2010 sebanyak 142.940 jiwa yang terdiri dari 72.078 laki-laki dan 70.862 perempuan. Jumlah penduduk Kecamatan Kota Manna 26.880 jiwa. Sebanyak 65,5\% penduduk Kabupaten Bengkulu Selatan

Tabel 1 Matricks SWOT

\begin{tabular}{|c|c|c|}
\hline $\begin{array}{l}\text { Faktor } \\
\text { Eksternal }\end{array}$ & $\begin{array}{l}\text { Opportunity }(\boldsymbol{O}) \\
\text { Menentukan faktor-faktor } \\
\text { peluang eksternal }\end{array}$ & $\begin{array}{l}\text { Threats }(\boldsymbol{T}) \\
\text { Menentukan faktor-faktor } \\
\quad \text { ancaman eksternal }\end{array}$ \\
\hline $\begin{array}{l}\text { Strengths }(S) \\
\text { Menentukan faktor-faktor } \\
\quad \text { kekuatan internal }\end{array}$ & $\begin{array}{l}\text { Strategi } \boldsymbol{S}-\boldsymbol{O} \\
\text { Menciptakan strategi yang } \\
\text { menggunakan kekuatan } \\
\text { untuk memanfaatkan } \\
\text { peluang }\end{array}$ & $\begin{array}{l}\text { Strategi } \boldsymbol{S}-\boldsymbol{T} \\
\text { Menciptakan strategi yang } \\
\text { mengguakan kekuatan untuk } \\
\text { mengatasi ancaman }\end{array}$ \\
\hline $\begin{array}{l}\text { Weakness }(\boldsymbol{W}) \\
\text { Menetukan faktor-faktor } \\
\text { kelemahan internal }\end{array}$ & $\begin{array}{l}\text { Strategi } \boldsymbol{W} \text { - } \boldsymbol{O} \\
\text { Menciptakan srtategi yang } \\
\text { meminimalkan } \\
\text { kelemahan } \\
\text { memanfaatkan peluang } \\
\text { yang ada }\end{array}$ & $\begin{array}{l}\text { Strategi } \boldsymbol{W}-\boldsymbol{T} \\
\text { Mencipatakan strategi yang } \\
\text { meminimalkan kelemahan } \\
\text { untuk menghindari ancaman }\end{array}$ \\
\hline
\end{tabular}


bekerja di Sektor Pertanian dan 34,5\% bekerja di sektor non Pertanian (Anonim, 2011), yang rinciannya ada pada tabel 2 .

Wilayah Penelitian: Tempat Pembuangan Akhir (TPA) sampah di Ibu Kota Kabupaten ini terletak di Desa Pagar Dewa Kecamatan Kota Manna Kabupaten Bengkulu Selatan berbatasan dengan:

- Sebelah Barat berbatasan dengan Sungai Sekunyit Kecil Desa Pagar Dewa

- Sebelah Timur berbatasan dengan Desa Air Kemang

- Sebelah Utara berbatasan dengan Desa Padang Serasan

- Sebelah Selatan berbatasan dengan Perumnas Pintu Langit Desa Tebat Kubu

Tabel 3 menunjukkan bahwa pegawai pada kantor Dinas Kebersihan Pertamanan dan Tata Kota cukup banyak walaupun didominasi oleh tenaga honorer yang berjumlah 146 orang. Pegawai yang banyak ini dapat diberdayakan untuk menciptakan kota yang bersih dan melakukan pengelolaan sampah dengan baik.

Tabel 2. Penduduk dan Mata pencaharian

\section{Pengelolaan Sampah di TPA}

Kabupaten Bengkulu Selatan memiliki 1 buah TPA dengan menerapkan sistem open dumping yang berlokasi di TPA Pagar Dewa, Kecamatan Kota Manna. Jarak TPA ke pusat kota $\pm 8 \mathrm{~km}$, sedang jarak TPA dengan pusat pelayanan sampah terdekat yaitu Kecamatan Kota Manna (0,5 $\mathrm{km})$, dan jarak pelayanan sampah terjauh yaitu Kecamatan Kedurang $(15 \mathrm{~km})$. TPA Pagar Dewa mempunyai luas 3,5 ha dan berada pada lembah yang dikelilingi oleh bukit dengan jarak ke areal perumahan terdekat sejauh $\pm 100 \mathrm{~m}$.

Tabel 4 menunjukkan bahwa sarana dan prasarana yang cukup walaupun mesin pencacah sampah dalam keadaan rusak. Dengan adanya sarana dan prasarana ini, diharapkan akan memperlancar dan meringankan pekerjaan.

Peraturan daerah yang mengatur tentang tarif retribusi pelayanan pasar adalah sebagai berikut:

a. Peraturan Daerah Kabupaten Bengkulu Selatan Nomor 02 Tahun 2011 Tentang Retribusi Jasa umum

b. Peraturan Daerah Kabupaten Bengkulu

\begin{tabular}{ll|c|c}
\hline No. & \multicolumn{1}{c|}{ Mata pencaharian } & Jumlah & Persentase (\%) \\
\hline 1. & PNS dan ABRI & 5.905 jiwa & 5,57 \\
2. & Bertani & 69.470 jiwa & 65,5 \\
3. & Dagang & 13.299 jiwa & 11,7 \\
4. & Pertambangan dan penggalian & 1.591 jiwa & 1,4 \\
5 & Lain-lain & 15.796 jiwa & 15,83 \\
\hline
\end{tabular}

Sumber: Bengkulu Selatan Dalam Angka, 2011.

Tabel 3. Jumlah Pegawai Dinas Kebersihan Pertamanan dan Tata Kota Kabupaten Bengkulu Selatan

\begin{tabular}{llc}
\hline No. & \multicolumn{1}{c}{ Uraian } & Jumlah \\
\hline 1. & Pegawai Kantor & 36 orang \\
2. & Tukang Sapu: & 6 orang \\
& - PNS & 11 orang \\
& - Honorer & 142 orang \\
3. & Sopir Mobil Pengangkut Sampah & 3 orang \\
& - PNS & 4 orang \\
& - Honorer & 31 orang \\
4. & Pegawai Pengumpul Sampah & 4 orang \\
5. & Operator Pencacah Sampah & $\mathbf{2 3 7 \text { orang }}$ \\
\hline
\end{tabular}

Sumber: Profil Dinas Kebersihan Pertamanan dan Tata Kota, 2011 
Tabel 4. Jumlah Sarana dan Prasarana Untuk Pembuangan Sampah

\begin{tabular}{llcc}
\hline No. & \multicolumn{1}{c}{ Uraian } & Jumlah & Keterangan \\
\hline 1. & Kontainer & 2 buah & \\
2. & Mobil/Truk angkutan & 7 buah & \\
3. & Gerobak sampah & 22 buah & \\
4. & Kotak sampah (Semen) & 120 buah & \\
5. & Kotak Sampah Organik/Anorganik (Fiber) & 125 buah & \\
6. & Mesin Pencacah Sampah & 2 buah & Rusak \\
\hline
\end{tabular}

Sumber: Profil Dinas Kebersihan Pertamanan dan Tata Kota, 2011

Selatan Nomor 23 Tahun 1998 Tentang

Retribusi Pelayanan Persampahan / Kebersihan.

Respon atau tanggapan masyarakat mengenai TPA tersebut adalah pada dasarnya mereka tidak menyetujui kalau lokasi TPA berada dekat pemukiman warga, karena menebar bau busuk, banyak lalat dan sampah yang beterbangan dari bak truk pengangkut sampah tersebut, otomatis akan mengganggu pemandangan dan kesehatan bagi masyarakat yang berada di sepanjang jalan menuju TPA.

Tempat Pembuangan akhir (TPA) Sampah Kabupaten Bengkulu Selatan terletak di Desa Pagar Dewa Kecamatan Kota Manna yang berjarak kira-kira $8 \mathrm{Km}$ dari Pusat Kota. Mempunyai luas 3,5 Ha dan berada pada lembah yang dikelilingi oleh bukit dan di sebelah barat di bawah jurang terdapat Sungai Sekunyit Kecil. Jarak TPA dengan pemukiman terdekat adalah 100 meter.

Sampah yang dibuang ke TPA lebih kurang 5 ton perhari. Sampah tersebut terdiri dari sampah organik dan sampah anorganik yang berasal dari seluruh penjuru ibukota kabupaten, yaitu dari perkantoran, tempat-tempat umum dan rumah tangga. Sesampainya di TPA, sampah dibiarkan begitu saja tanpa dilakukan pengolahan, sehingga menebarkan bau busuk dan banyak dikerumuni lalat serta serangga lainnya, bahkan banyak pula yang hanyut ke sungai di bawah TPA.

Dalam penelitian ini sampel terdiri dari 60 responden yang merupakan masyarakat yang bermukim di sekitar (sekeliling) TPA dengan latar belakang yang berbeda-beda. Berdasarkan pekerjaannya, responden terdiri dari PNS sebanyak 27 orang, petani 19 orang, Pedagang 13 orang dan pegawai swasta sebanyak 1 orang. Sedangkan kalau dilihat berdasarkan pendidikan responden, terdiri dari tamatan Strata 2 (S2) 2 orang, tamat Strata 1 (S1) 17 orang, tamat SLTA 25 orang, tamat SLTP 7 orang, tamat SD juga 7 orang dan tidak bersekolah 2 orang. Responden berumur dari 26 tahun sampai umur 68 tahun.

Hasil Penelitian Terhadap Kekuatan, Kelemahan, Peluang dan Ancaman (SWOT) Pada Strategi Pengelolaan Sampah di TPA Kabupaten Bengkulu Selatan.

\section{Kekuatan}

Berdasarkan penelitian yang dilakukan, diketahui kekuatan yang dimiliki Dinas Kebersihan Pertamanan dan Tata Kota Kabupaten Bengkulu Selatan, yang merupakan internal Dinas Kebersihan Pertamanan dan Tata Kota Kabupaten Bengkulu Selatan adalah:

a. Adanya dukungan dari Pemerintah Daerah Kabupaten Bengkulu Selatan. dilihat dari tanggapan responden 52\% menyatakan setuju, $42 \%$ sangat setuju, dan 6\% menyatakan tidak setuju.

b. Tersedianya Sumber Daya Manusia (SDM) yang cukup banyak yaitu pegawai Dinas Kebersihan Pertamanan dan Tata Kota Kabupaten Bengkulu Selatan yang dapat dimanfaatkan untuk mengoptimalkan strategi pengelolaan sampah di TPA Desa Pagar Dewa dilihat dari $66 \%$ responden menyatakan setuju, $27 \%$ responden menyatakan sangat setuju dan $7 \%$ responden kurang setuju. 
c. Tersedianya cukup kotak sampah yang digunakan untuk menampung sampahsampah disetiap penjuru Ibu Kota Kabupaten Bengkulu Selatan dilihat dari $68 \%$ menyatakan setuju, 19\% sangat setuju dan $13 \%$ tidak setuju.

\section{Kelemahan}

Kelemahan pada Dinas Kebersihan Pertamanan dan Tata Kota merupakan permasalahan internal Dinas Koperasi Perindustrian dan Perdagangan dalam usaha optimalisasi pengelolaan sampah di TPA adalah Pegawai Dinas Kebersihan Pertamanan dan Tata Kota kurang aktif dan belum diberdayakan maksimal.

\section{Peluang}

Peluang yang dimiliki Dinas Kebersihan Pertamanan dan Tata Kota dalam pengelolaan sampah di Kabupaten Bengkulu Selatan yang merupakan faktor eksternal Dinas Kebersihan Pertamanan dan Tata Kota Kabupaten Bengkulu Selatan adalah Sampah organik dapat dijadikan pupuk kompos dan makanan ternak.

\section{Strategi (S-O)}

Memanfaatkan kekuatan yang dimiliki Dinas Kebersihan Pertamanan dan Tata Kota Kabupaten Bengkulu Selatan dan berusaha secara maksimal untuk mendapatkkan peluang yang ada, dengan cara berkoordinasi dengan Pemerintah Daerah Kabupaten Bengkulu Selatan agar menyediakan lahan untuk pengomposan yang selanjutnya pupuk kompos tersebut bisa dijual, memanfaatkan pegawai Dinas Kebersihan Pertamanan dan Tata Kota yang cukup banyak untuk bekerja secara aktif dan berdaya guna, memisahkan sampah organik dan anorganik, yang selanjutnya dapat dijual untuk dijadikan makanan ternak, bahan baku kosmetika dan pupuk kompos (sampah organik) serta mendaur-ulang atau menjual sampah anorganik. Memanfaatkan dan menempatkan kotak sampah yang cukup tersedia di tempat-tempat yang strategis dan dengan cara memberi tulisan pada kotak sampah tersebut (sampah organik atau anorganik), sehingga antara sampah organik dan anorganik langsung terpisah.

\section{Strategi (W-O)}

Strategi W-O (WeaknesesOpportunity), strategi ini adalah mengatasi sebagian kelemahan guna menangkap peluang. Sebagaimana sudah dikemukakan sebelumnya bahwa kelemahan pada pengelolaan sampah di TPA Kabupaten Bengkulu Selatan adalah Pegawai Dinas Kebersihan Pertamanan dan Tata Kota masih kurang aktif dalam bekerja dan belum diberdayakan maksimal, pendistribusian SDM masih kurang tepat, serta masih kurangnya sosialisasi tentang sampah organik dan anorganik dan cara pemisahannya. Sedangkan peluangnya adalah sampah dapat dijadikan makanan ternak dan pupuk kompos, sampah yang berasal dari tulang hewan dapat dijual untuk bahan baku kosmetika serta sampah anorganik dapat dijual atau didaur ulang. Dengan adanya kelemahan dan peluang yang ada, strategi W-O dapat dilakukan dengan cara:

a. SDM yang kurang aktif ddan beluum diberdayakan maksimal, dapat diatasi dengan cara memberikan pengarahan dan pelatihan tentang pengolahan sampah yang baik.

b. Pendistribusian SDM yang kurang tepat, dapat diatasi dengan cara menempatkan SDM sesuai dengan bidang ilmunya, misalnya merekrut pegawai yang berbasis pendidikan kesehatan lingkungan dan yang mengerti tentang pengelolaan sampah.

c. Masih kurangnya sosialisasi kepada masyarakat tentang sampah organik dan anorganik serta cara pemisahannya, dapat diatasi dengan cara melakukan sosialisasi kepada masyarakat.

\section{Strategi W-T}

Staretgi W-T (Weakness-threat), strategi ini adalah menutupi kelemahan 
guna mengatasi ancaman. Kelemahan pengelolaan sampah di TPA Kabupaten Bengkulu Selatan adalah: Pegawai Dinas Kebersihan Pertamanan dan Tata Kota masih kurang aktif dalam bekerja dan belum diberdayakan maksimal, Pendistribusian SDM masih kurang tepat serta masih kurangnya sosialisasi tentang sampah organik dan anorganik serta cara pemisahannya. Sedangkan ancaman adalah kemungkinan gagalnya pengelolaan sampah di TPA Kabupaten Bengkulu Selatan tersebut adalah karena: sarana angkutan masih kurang, belum tersedianya lahan untuk pengomposan, susahnya mencari lahan untuk lokasi TPA yang baru, belum dipisahkannya antara sampah organik dan anorganik,gaji pegawai honorer asih sangat minim dan belum ada SDM yang menguasai teknik mesin pengelola sampah dan tenaga ahli di bidang pengelolaan sampah. Hal ini dapat diatasi dengan cara melakukan koordinasi dengan Pemerintah Daerah agar menambah sarana angkutan sampah dan menyediakan lahan untuk pengomposan serta menyediakan mesin untuk pengelolaan sampah dan proses pendaurulangan, mensosialisasikan pemisahan sampah organik dan anorganik, menambah anggaran untuk menaikan gaji pegawai honorer agar mereka giat bekerja dan merekrut SDM yang menguasai teknik mesin pengelola sampah dan tenaga ahli dalam bidang pengelolaan sampah.

\section{Strategi S-T}

Strategi S-T (Strengh-Threat) adalah strategi memanfaatkan kekuatan guna mengatasi ancaman. Dimana kekuatan adalah memanfaatkan dukungan dari Pemerintah Daerah, memanfaatkan pegawai Dinas Kebersihan Pertamanan dan Tata Kota yang cukup serta kotak sampah yang cukup tersedia untuk melakukan pengelolaan sampah di TPA Kabupaten Bengkulu Selatan. Dengan adanya kekuatan ini, maka ancaman yang terjadi bisa diatasi, misalnya berkoordinasi dengan Pemerintah Daerah agar dapat menambah sarana angkutan sampah dan menyediakan lahan untuk proses pengomposan, menambah anggaran untuk menaikkan gaji pegawai honorer, dan merekrut SDM yang menguasai teknik mesin pengolah sampah dn tenaga ahli dalam bidang pengelolaan sampah serta dengan jumlah pegawai Dinas Kebersihan Pertamanan dan Tata Kota yang cukup dapat memberi penyuluhan/mensosialisasikan kepada masyarakat tentang sampah organik dan anorganik serta cara pemisahannya.

Dengan memanfaatkan seluruh kekuatan yang ada, maka pengelolaan sampah di TPA Kabupaten Bengkulu Selatan dapat dilaksanakan dengan baik, disamping mengurangi akibat dari dampak pembuangan sampah di TPA, juga dapat menambah income dari pengolahan sampah tersebut.

Berdasarkan hasil penelitian dan analisis, diketahui bahwa dalam melakukan pengelolaan sampah di TPA Kabupaten Bengkulu Selatan mempunyai kekuatan: adanya dukungan dari Pemerintah Daerah untuk melakukan pengelolaan sampah di TPA dengan baik, jumlah pegawai Dinas Kebersihan Pertamanan dan Tata Kota yang cukup untuk mengatur segala sesuatunya, sehingga proses pengelolaan sampah dapat berjalan dengan baik serta cukup tersedianya kotak sampah di seluruh penjuru kota, sehingga diharapkan masyarakat dapat membuang sampah pada tempat yang telah ditentukan (sampah organik dan anorganik) sehingga sampah tersebut langsung terpisah untuk mempermudah pengolahan selanjutnya. Namun dalam melakukan kegiatan pengelolaan sampah di TPA ini mempunyai kelemahan pada pegawai Dinas Kebersihan Pertamanan dan Tata Kota yang kurang aktif dan berdaya guna, yang umumnya belum mampu melakukan pengelolaan sampah dengan baik, pendistribusian SDM yang kurang tepat serta masih kurangnya sosialisasi tentang sampah organik dan anorganik serta cara pemisahannya.

Peluang untuk pengelolaan sampah dengan baik cukup besar, yaitu samaph dapat dijadikan makanan ternak dan pupuk kompos, sampah yang berasal dari tulang hewan dapat dijadikan bahan baku kosmetika dan sampah anorganik bisa didaur ulang. Namun ancaman pada pengelolaan sampah di TPA ini adalah 
masih kurangnya sarana angkutan sampah, masih belum tersedia lahan untuk proses pengomposan, belum dipisahkannya sampah organik dan anorganik, gaji pegawai honorer yang masih sangat minim serta belum adanya SDM yang menguasai teknik mesin pengelola sampah dan tenaga ahli di bidang pengelolaan sampah.

Melalui analisis kekuatan, kelemahan, peluang dan ancamanan pada pengelolaan sampah di TPA ini, maka strategi yang tepat untuk mengoptimalkan pengelolaan sampah adalah menggunakan Strategi S-O (Strengh-Opportunity) yaitu memanfaatkan seluruh kekuatan yang ada untuk mendapatkan peluang yaitu dengan adanya dukungan dari Pemerintah Daerah, maka Dinas Kebersihan Pertamanan dan Tata Kota dapat berkoordinasi agar Pemerintah daerah menambah sarana pengangkut sampah, mesin pengolah sampah dan menyediakan lahan untuk pengomposan, tersedianya pegawai Dinas Kebersihan Pertamanan dan Tata Kota yang cukup untuk melakukan pengelolaan sampah dengan baik dan tersedianya kotak sampah yang cukup di seluruh penjuru kota, sehingga diharapkan sampah dari masyarakat maupun sampah di tempattempat umum tidak berserakan dan langsung terpisah antara sampah organik dan anorganik. Dengan adanya kekuatan ini, maka diharapkan peluang yang ada bisa kita dapatkan, sehingga disamping dapat meminimalisir akibat dari dampak pembuangan sampah di TPA, juga dapat menambah penghasilan dari penjualan dan pendaur-ulangan sampah tersebut.

\section{KESIMPULAN}

Strategi yang direkomendasikan untuk mengelola sampah di TPA Kabupaten Bengkulu Selatan yaitu memanfaatkan seluruh kekuatan yang dimiliki Dinas Kebersihan Pertamanan dan Tata Kota yaitu adanya dukungan dari Pemerintah Daerah dan jumlah Sumber Daya Manusia
(SDM) yang cukup, diharapkan dapat mengelola sampah dengan baik yang akan menambah pendapatan daerah, misalnya dengan menjual pupuk kompos. Sampah organik untuk makanan ternak dan mensosialisasikan pemisahan sampah organik dan anorganik agar bisa dijadikan pupuk kompos dan didaur ulang. Pembuatan/pembangunan unit pengolahan kompos dengan melibatkan masyarakat setempat (memberdayakan masyarakat atau pemulung).

\section{DAFTAR PUSTAKA}

Anonim, 1998. Peraturan Daerah Kabupaten Bengkulu Selatan Nomor 23 Tahun 1998 Tentang Retribusi Pelayanan

Persampahan/Kebersihan, Bagian Hukum Pemda Kabupaten Bengkulu Selatan.

Anonim, 2000, Nusantara, Tim suhus kertaseni, Berkreasi Dengan Kertas Daur Ulang, puspa swara, Jakarta.

Anonim, 2008. Undang-Undang No.18 Tahun 2008, Tentang Pengelolaan Sampah, Setneg Republik Indonesia, Jakarta

Anonim, 2010, Bengkulu Selatan Dalam Angka 2010, Badan Pusat Statistik Bengkulu Selatan

Anonym, 2011, Laporan Pemantauan Kualitas Air di Kabupaten Bengkulu Selatan. Kantor Lingkungan Hidup Bengkulu Selatan

Anonim, 2011. Peraturan Daerah Kabupaten Bengkulu Selatan Nomor 02 Tahun 2011 Tentang Retribusi Jasa umum, Bagian Hukum Pemda Kabupaten Bengkulu Selatan.

Purwanti, E, 2007, Sampah Jadi Uang, Cetakan Pertama, Saka Mitra Kompetensi, Jakarta.

Rangkuty, F. 2000, Analisis SWOT Tehnik Membedah Kasus Bisnis, PT. Gramedia Pustaka Utama, Jakarta. 